\title{
A retrospective study of the relationship between postoperative urine output and one year transplanted kidney function
}

Joungmin Kim, Taehee Pyeon, Jeong II Choi, Jeong Hyeon Kang, Seung Won Song, Hong-Beom Bae* (iD and Seongtae Jeong*

\begin{abstract}
Background: Kidney transplantation (KT) is the most obvious method of treating a patient with end-stage renal disease. In the early stages of KT, urine production is considered a marker of successful reperfusion of the kidney after anastomosis. However, there is no clear conclusion about the relationship between initial urine output after KT and 1-year renal function. Thus, we investigated the factors that affect 1-year kidney function after KT, including urine output.

Methods: This retrospective study investigated the relationship between urine output in the 3 days after $\mathrm{KT}$ and transplanted kidney prognosis after 1-year. In total, 291 patients (129 living-donor and 162 deceased-donor transplant recipients) were analyzed; 24-h urine volume per body weight (in kilograms) was measured for 3 days postoperatively. The estimated glomerular filtration rate (eGFR), determined by the Modification of Diet in Renal Disease algorithm, was used as an index of renal function. Patients were grouped according to eGFR at 1-year after KT: a good residual function group, eGFR $\geq 60$, and a poor residual function group, eGFR $<60$.

Result: Recipients' factors affecting 1-year eGFR include height $(P=0.03)$, weight $(P=0.00)$, and body mass index $(P=0.00)$. Donor factors affecting 1-year eGFR include age $(P=0.00)$ and number of human leukocyte antigen (HLA) mismatches $(P=0.00)$. The urine output for 3 days after $K T$ (postoperative day $1 ; 2$ and 3 ) was associated with 1-year eGFR in deceased-donor $(P=0.00 ; P=0.00$ and $P=0.01)$. And, postoperative urine output was associated with the occurrence of delayed graft function (area under curve (AUC) $=0.913$; $A \cup C=0.984$ and $A \cup C=0.944)$.
\end{abstract}

Conclusion: Although postoperative urine output alone is not enough to predict 1-year GFR, the incidence of delayed graft function can be predicted. Also, the appropriate urine output after KT may differ depending on the type of the transplanted kidney.

Trial registration: Clinical Research Information Service of the Korea National Institute of Health in the Republic of Korea (KCT0003571).

Keywords: Kidney transplantation, Urine output, Graft survival, Glomerular filtration rate

\footnotetext{
*Correspondence: nextphil2@hanmail.net; anesjst@jnu.ac.kr

Department of Anesthesiology and Pain Medicine, Chonnam National

University Medical School; Chonnam National University Hospital, 42

Jebong-ro Dong-gu, Gwangju 61469, South Korea
}

(c) The Author(s). 2019 Open Access This article is distributed under the terms of the Creative Commons Attribution 4.0 International License (http://creativecommons.org/licenses/by/4.0/), which permits unrestricted use, distribution, and reproduction in any medium, provided you give appropriate credit to the original author(s) and the source, provide a link to the Creative Commons license, and indicate if changes were made. The Creative Commons Public Domain Dedication waiver (http://creativecommons.org/publicdomain/zero/1.0/) applies to the data made available in this article, unless otherwise stated. 


\section{Background}

The incidence of end-stage renal disease (ESRD) is increasing with the prolonged life span and raised prevalence of chronic diseases, such as diabetes and hypertension [1]. Kidney transplantation (KT) is a proven approach to improve quality of life and prolong life expectancy in patients with ESRD [2]. Therefore, it has become important to maintain the function of the transplanted kidney due to the imbalance caused by limited supply and increasing demand. During KT, recipients have been given mannitol [3], dopamine [4], furosemide [5], and fluid loading [6] to enhance transplanted-kidney function. A few of these measures have increased the long-term survival rate of transplanted organs.

Early detection and prevention of renal functional decline are important for the maintenance of normal graft function. Several tests, including urine-based measurements, can be used to evaluate the function of the kidneys. Urine tests are suitable for clinical applications because the necessary samples are easy to obtain. They involve the measurement of specific substances in the urine, such as kidney injury molecule-1 [7], or measurement of the urine volume. In early stages of $\mathrm{KT}$, urine production is considered to be a sign of successful reperfusion after anastomosis $[8,9]$. The use of perioperative diuretics to increase urine volume differs among centers with respect to type and dose $[10,11]$. Some reports have shown that long-term prognosis can be predicted by urine volume after KT [12, 13]. However, excessive diuresis may occasionally result in a lack of circulating plasma volume or electrolyte imbalances [14].

In general, it is known that the glomerular filtration rate (GFR) is an excellent indicator of overall kidney function [15]. GFR measurements using exogenous markers such as inulin clearance are known to be the most accurate methods. However, use of these markers is laborious and expensive, and thus is rare in clinical practice. Conversely, although there is some inaccuracy, endogenous markers such as serum creatinine $(\mathrm{Cr})$ or cystatin $\mathrm{C}$ are used to assess kidney function. Limiting factors for using $\mathrm{Cr}$ as a marker of GFR include weight, age, sex and race. The Modification of Diet in Renal Disease (MDRD) equation for GFR estimation was derived from 1628 patients with chronic kidney disease (mean GFR, $40 \mathrm{~mL} / \mathrm{min} / 1.73$ $\mathrm{m}^{2}$ ) to overcome some limitations [16].

Transplanted kidneys are known to produce large amounts of urine in the initial stage after transplantation [17]. No criterion for the appropriate urine volume after KT has been established. We aimed to compare urine volume in the 3 days after surgery and the estimated glomerular filtration rate (eGFR) at 1 year postoperatively in patients who received KT.

\section{Methods}

\section{Study design and ethical statement}

This single-center retrospective cohort study was conducted using the electronic medical records of Chonnam National University Hospital. This registry retrospectively collects data regarding recipients' characteristics and outcomes. Adult patients (age $\geq 20$ years) who underwent KT in our center during the 10-year period between 1 January 2008 and 31 December 2017 were included.

The institutional review board of Chonnam National University Hospital approved the study protocol (CNUH-2019-018), and the study was registered with the Clinical Research Information Service of the Korea National Institute of Health in the Republic of Korea (KCT0003571), which belongs to the World Health Organization Registry Network.

\section{Data collection}

In total, 303 kidney transplants, including re-transplantations, were performed during the study period. Patients were excluded from the analysis if they lacked medical records for the first year after surgery, due to death or loss to follow-up; patients aged $<20$ years were also excluded. The preoperative information collected was age, sex, height, weight, body mass index (BMI), duration of dialysis, method of dialysis, eGFR, diabetes mellitus (DM) status, hypertension (HTN) status, hepatitis B virus status, hepatitis $C$ virus status, and type of donated kidney. eGFRs were estimated using the MDRD equation. In addition, the characteristics of donated kidney such as age, Creatinine, DM, HTN, and human leukocyte antigen (HLA) mismatch, incidence of delayed graft function (DGF) were also investigated. DGF was defined as hemodialysis performed within 1 week after surgery. Nephropathy was defined as primary kidney disorder, such as IgA nephropathy or autosomal polycystic kidney, but not secondary kidney disorder due to HTN or DM. Our hospital usually measures the amount of urine for $24 \mathrm{~h}$ during the 3 days after KT; those data were used in the present study. The total volume (in milliliters) of urine collected over $24 \mathrm{~h}$ was divided by the body weight (in kilograms) of the patient. Follow-up data (e.g., eGFR, graft rejection, and viral infection) were collected at 1 year after KT. Graft rejection episodes were defined as biopsy-proven rejection or clinically suspected acute rejection that was improved by empirical steroid pulse therapy. Patients were considered to be positive for viral infection when cytomegalovirus (CMV), Epstein-Barr virus (EBV), or BK polyomavirus (BKV) was detected after KT.

\section{Outcomes}

Chronic kidney disease (CKD) is defined as GFR $<60$ $\mathrm{mL} / \mathrm{min} / 1.73 \mathrm{~m}^{2}$ for 3 months or more [18]. This criterion can be applied to KT patients [19] and, the degree of GFR impairment at 1 year post-KT has prognostic value and is associated with lower GFR at 5 years, higher risk 
of eventual graft failure, and cardiovascular death [20]. The patients were grouped according to eGFR at 1 year after KT: a good residual function group, eGFR $\geq 60$, and a poor residual function group, eGFR $<60$. The primary goal was to assess the relationship between the eGFR at 1 year postoperatively and urine output during the 3 days after KT. The secondary goal was to assess the association of eGFR at 1 year after KT with other patient data, such as donated kidney's demographics, fluid and diuretic dose, rejection and infection.

\section{Statistical analysis}

For demographic data, the independent two sample ttest for normal continuous data or the Wilcoxon ranksum test for non-normal continuous data were used as appropriate. The normality was verified by Shapiro-Wilk test. The categorical data was analyzed by the Chisquared test or Fisher's Exact test. A subgroup analysis according to the type of transplanted kidney was performed. A bonferroni correction was used to adjust type I error for multiple comparisons in subgroup analysis and $P$ values $<.025$ was considered as statistically significant. The analysis of usefulness of postoperative urine output for the prediction of delayed graft function and residual renal function at 1 year after transplantation used receiver-operating-characteristic (ROC) curve techniques. The statistical analysis was performed using $R$ version 3.6.0 (The R Foundation for Statistical Computing, Vienna, Austria).

\section{Results}

During the study period, 303 kidney transplants were performed. Four patients aged $<20$ years were excluded. Eight patients who were lost to follow-up or who died within 1 year after KT were also excluded. Finally, a total of 291 patients were included in the analysis (Fig. 1).

\section{Baseline characteristics of the study population}

Demographic data of KT recipients were not statistically different between two groups except height, weight and BMI (Table 1). Age and HLA mismatch were statistically significant between the two groups in the donated kidney's demographic data (Table 2).

\section{Comparison with 1 year eGFR and postoperative urine output, amounts of fluid and diuretics}

The postoperative urine output and the overall 1 year prognosis of the transplanted kidney were related to postoperative 3 days in all patients (Table 3 ). Interestingly, in the subgroup analysis, urine output and residual kidney function was not associated with a living-donor kidney group, whereas in patients who received a deceased-donor kidney group showed association was evident on all 3 days postoperatively.

Amounts of fluid administration for 3 days after surgery were compared (Table 4). The amount of fluid administered was larger in the good residual function group. This difference is thought to be due to postoperative fluid therapy in our institution. Patients receive $15 \mathrm{ml} / \mathrm{kg}$ for $1 \mathrm{~h} \mathrm{im}$ mediately after surgery and an additional dose of fluids

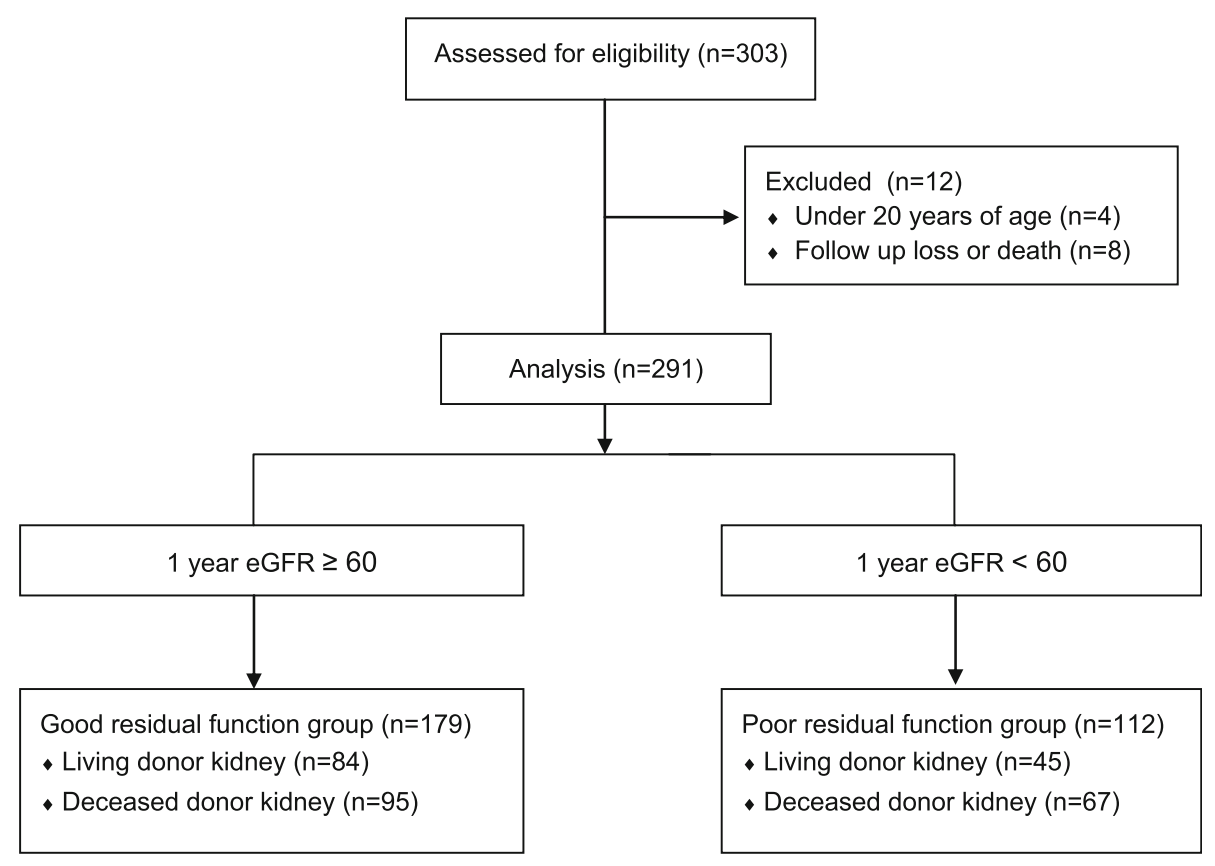

Fig. 1 Data collection 
Table 1 Demographic data of kidney recipients

\begin{tabular}{|c|c|c|c|}
\hline & Good residual function group $(n=179)$ & Poor residual function group $(n=112)$ & $P$ value \\
\hline Age & $47.0[38.0 ; 54.5]$ & $47.0[38.5 ; 55.0]$ & .84 \\
\hline Gender (male/female) & $111(62.0 \%) / 68$ (38.0\%) & 79 (70.5\%) / $33(29.5 \%)$ & .18 \\
\hline Height (cm) & $164.0[158.0 ; 171.0]$ & $167.5[160.0 ; 172.0]$ & .03 \\
\hline Weight (kg) & $60.5 \pm 9.7$ & $65.2 \pm 12.2$ & .00 \\
\hline BMI & $22.3 \pm 3.0$ & $23.4 \pm 3.4$ & .00 \\
\hline Pre-transplant dialysis duration (month) & $36.0[5.0 ; 72.0]$ & $48.0[12.0 ; 72.0]$ & .12 \\
\hline Pre-transplant dialysis type & & & .53 \\
\hline$H D$ & $108(60.3 \%)$ & $66(58.9 \%)$ & \\
\hline PD & $44(24.6 \%)$ & $33(29.5 \%)$ & \\
\hline $\mathrm{HD}+\mathrm{PD}$ & $10(5.6 \%)$ & $7(6.2 \%)$ & \\
\hline None & $17(9.5 \%)$ & $6(5.4 \%)$ & \\
\hline $\begin{array}{l}\text { Pre-operative eGFR } \\
\left(\mathrm{ml} / \mathrm{min} / 1.73 \mathrm{~m}^{2}\right)\end{array}$ & $5.5[4.3 ; 7.6]$ & $5.3[4.0 ; 7.0]$ & .15 \\
\hline KT history & & & .59 \\
\hline 1 st & $167(93.3 \%)$ & $107(95.5 \%)$ & \\
\hline 2nd & $12(6.7 \%)$ & $5(4.5 \%)$ & \\
\hline$A B O$ incompatibility & & & .43 \\
\hline Matched & $170(95.0 \%)$ & $103(92.0 \%)$ & \\
\hline Un-matched & $9(5.0 \%)$ & $9(8.0 \%)$ & \\
\hline Donated Kidney & & & .31 \\
\hline Living & $84(46.9 \%)$ & $45(40.2 \%)$ & \\
\hline Deceased & $95(53.1 \%)$ & 67 (59.8\%) & \\
\hline HBV positive & $15(8.4 \%)$ & $13(11.6 \%)$ & .48 \\
\hline HCV positive & $3(1.7 \%)$ & $2(1.8 \%)$ & 1.00 \\
\hline Nephropathy positive & $10(5.6 \%)$ & $9(8 \%)$ & .56 \\
\hline HTN positive & $155(86.6 \%)$ & $103(92.0 \%)$ & .22 \\
\hline DM positive & $44(24.6 \%)$ & $30(26.8 \%)$ & .77 \\
\hline
\end{tabular}

Data are present as mean \pm standard deviation or median [ $95 \%$ confidence interval] or number (\%)

Good residual function group: 1 year eGFR $\geq 60$, Poor residual function group: 1 year eGFR $<60$

$B M I$ Body mass index, HD Hemodialysis, PD Peritoneal dialysis, eGFR Estimated glomerular filtration rate, KT Kidney transplantation, HBV Hepatitis B virus, HCV

Hepatitis C virus, HTN Hypertension, DM Diabetes mellitus

given as same volume of urine output for 3 days. The basic maintenance of fluid was $1 \mathrm{ml} / \mathrm{kg} / \mathrm{hr}$. and the amount was reduced as the diet progressed. All of the administered fluids were crystalloids such as normal saline or Hartman solution, and the choice of fluid was determined by the electrolyte concentration of the patient.

There was no statistical difference between the two groups when comparing the amount of diuretics (furosemide, mannitol) administered for 3 days and 1 year eGFR (Tables 5 and 6).

\section{Prediction of DGF and 1 year residual graft function through postoperative urine output}

Postoperative day 2 urine output was the highest in the correlation between 3 days postoperative urine output and DGF development (Table 7).
The relationship between postoperative urine output at 3 days and 1 year eGFR was analyzed by ROC curve (Fig. 2).

\section{Comparison with 1 year eGFR and postoperative rejection, viral infection}

Good residual function group was associated with fewer rejection episodes in all patients; subgroup analysis yielded similar findings (Table 8).

Good residual function group was also associated with fewer viral infections in all patients; subgroup analysis yielded similar findings (Table 9). The cohort contained 45 patients with CMV infection, 9 patients with BK infection, 6 patients with CMV and BK co-infection, and no patient with EBV infection (data not shown). 
Table 2 Donated kidney characteristics

\begin{tabular}{|c|c|c|c|}
\hline & $\begin{array}{l}\text { Good residual } \\
\text { function group }\end{array}$ & $\begin{array}{l}\text { Poor residual } \\
\text { function group }\end{array}$ & $P$ value \\
\hline \multicolumn{4}{|l|}{$\overline{\text { All }}$} \\
\hline & $(n=179)$ & $(n=112)$ & \\
\hline Age & $40.0[27.5 ; 49.0]$ & $50.0[44.0 ; 56.0]$ & .00 \\
\hline Creatinine (mg/dl) & $0.9[0.7 ; 1.2]$ & $0.9[0.7 ; 1.2]$ & .45 \\
\hline DM positive & $5(2.8 \%)$ & $9(8.0 \%)$ & .08 \\
\hline HTN positive & $210.1 \pm 94.3$ & $176.9 \pm 94.5$ & .04 \\
\hline HLA mismatching & $3.0[2.5 ; 4.0]$ & $4.0[3.0 ; 5.0]$ & .00 \\
\hline DGF positive & $4(2.2 \%)$ & $4(3.6 \%)$ & .75 \\
\hline \multicolumn{4}{|l|}{ Living donor kidney } \\
\hline & $(n=84)$ & $(n=45)$ & \\
\hline Age & $40.2 \pm 11.7$ & $48.4 \pm 9.2$ & .00 \\
\hline Creatinine (mg/dl) & $0.8[0.6 ; 0.9]$ & $0.8[0.6 ; 0.9]$ & .80 \\
\hline DM positive & $0(0.0 \%)$ & $1(2.2 \%)$ & .75 \\
\hline HTN positive & $7(8.3 \%)$ & $3(6.7 \%)$ & 1.00 \\
\hline HLA mismatching & $3.0[2.0 ; 3.0]$ & $3.0[3.0 ; 4.0]$ & .02 \\
\hline DGF positive & $2(2.4 \%)$ & $0(0.0 \%)$ & .76 \\
\hline \multicolumn{4}{|l|}{ Deceased donor kidney } \\
\hline & $(n=95)$ & $(n=67)$ & \\
\hline Age & $39.0[24.0 ; 50.5]$ & $49.5[44.0 ; 56.0]$ & .00 \\
\hline Creatinine (mg/dl) & $1.0[0.7 ; 1.5]$ & $1.1[0.8 ; 1.4]$ & .65 \\
\hline DM positive & $5(5.3 \%)$ & $8(11.9 \%)$ & .21 \\
\hline HTN positive & $12(12.6 \%)$ & $13(19.4 \%)$ & .34 \\
\hline HLA mismatching & $3.0[3.0 ; 4.0]$ & $4.0[3.0 ; 5.0]$ & .02 \\
\hline DGF positive & $2(2.1 \%)$ & $4(6.0 \%)$ & .39 \\
\hline
\end{tabular}

Data are present as mean \pm standard deviation or median $[95 \%$ confidence interval]

HTN Hypertension, DM Diabetes mellitus, HLA Human leukocyte antigen

\section{Discussion}

Early diuresis after KT is a good indicator of transplanted kidney function [21]. However, the relationship between initial urine output and long-term survival of the transplanted kidney is unclear. Aigner et al. [22] reported that the initial postoperative urine volume was an accurate predictor of delayed graft function (DGF). There are many definitions, but DGF is usually defined as using dialysis the first week after surgery [23]. The long-term prognosis of a transplanted kidney is also related to postoperative urine output [12, 13]. However, Chisholm et al. [24] reported that they found no association between initial diuresis and 12-month graft survival. The present study shows that the 1 year eGFR after KT was associated with urine outputs on postoperative 3 days. However, in subgroup analysis, urine output on all three postoperative days was significantly associated with residual graft function in deceased-donor KT but not in living-donor KT.

In this study, deceased-donor kidney recipient was associated with postoperative urine output and 1-year eGFR. Urine production begins as blood moves to the
Table 3 Relationship of $1 \mathrm{yr}$ residual kidney function and postoperative urine output ( $\mathrm{ml} / \mathrm{kg} / \mathrm{hr}$ ) of $1 \mathrm{st}, 2 \mathrm{nd}$, and $3 \mathrm{rd}$ day

\begin{tabular}{llll}
\hline & $\begin{array}{l}\text { Good residual function } \\
\text { group }\end{array}$ & $\begin{array}{l}\text { Poor residual function } \\
\text { group }\end{array}$ & $\begin{array}{l}P \\
\text { value }\end{array}$ \\
\hline All & & & \\
& $(n=179)$ & $(n=112)$ & \\
& $13.2[10.0 ; 17.8]$ & $9.5[5.8 ; 15.2]$ & .00 \\
POD1 & & $7.1[5.1 ; 9.3]$ & .00 \\
POD2 & $8.2[6.1 ; 10.7]$ & $6.1[4.2 ; 7.9]$ & .01 \\
& $6.9[5.2 ; 8.8]$ & &
\end{tabular}

Living donor kidney

\begin{tabular}{|c|c|c|c|}
\hline & $(n=84)$ & $(n=45)$ & \\
\hline POD1 & $16.8[12.9 ; 20.4]$ & $14.8[11.4 ; 18.8]$ & .06 \\
\hline POD2 & $8.0[6.3 ; 10.3]$ & $8.0[6.0 ; 9.1]$ & .42 \\
\hline POD3 & $6.8[5.1 ; 8.8]$ & $6.8[5.7 ; 7.8]$ & .61 \\
\hline \multicolumn{4}{|c|}{ Deceased donor kidney } \\
\hline & $(n=95)$ & $(n=67)$ & \\
\hline POD1 & $11.1[7.1 ; 14.5]$ & $7.2[4.5 ; 10.1]$ & .00 \\
\hline POD2 & $8.3[5.9 ; 11.2]$ & $6.9[4.1 ; 9.3]$ & .00 \\
\hline POD3 & $6.9[5.2 ; 9.0]$ & $5.7[3.4 ; 8.1]$ & .01 \\
\hline
\end{tabular}

Data are present as median [95\% confidence interval]

Good residual function group: 1 year $\mathrm{eGFR} \geq 60$, Poor residual function group: 1 year eGFR $<60$

$P O D$ Postoperative day

glomerulus and is filtered out of the glomerular barrier. The renin-angiotensin-aldosterone system (RAAS) regulates renal blood flow and the GFR by modulating resistance of the renal afferent and efferent arterioles. Regardless of the type of fluid, when a sufficient volume of fluid enters the blood vessel, the amounts of renin and aldosterone decrease and urine volume increases [25]. Renin and aldosterone increase due to prolonged cold ischemic time during $\mathrm{KT}$ in deceased-donor kidneys. This elevation is maintained until the second postoperative day [26]. The differences in urine volume and graft function between living-donor and deceased-donor kidney recipients in our study may be attributed to activation of the RAAS by prolonged cold ischemic time. Koller et al. [27] reported that $41 \%$ of deceased-donor kidney transplants were complicated by DGF. They found that deceased-donor kidneys exhibited higher plasma renin and angiotensin II levels after KT, compared with living-donor kidneys (renin, 5.1 vs. $2.6 \mathrm{ng} /$ $\mathrm{mL} / \mathrm{h}, \quad P<.02$; angiotensin II, 62.8 vs. $48.5 \mathrm{pg} / \mathrm{mL}$, $P<.01)$. In addition, Oberbauer et al. [28] reported that 10 -year graft survival rates were $59 \%$ in angiotensin- 
Table 4 Relationship of residual kidney function and postoperative fluid therapy ( $\mathrm{ml} / \mathrm{kg} / \mathrm{hr}$ ) of 1st, 2nd, and 3rd day

\begin{tabular}{|c|c|c|c|}
\hline & Good residual function group & Poor residual function group & $P$ value \\
\hline \multicolumn{4}{|l|}{ All } \\
\hline & $(n=179)$ & $(n=112)$ & \\
\hline POD1 & $13.9[9.9 ; 19.1]$ & $11.2[7.5 ; 16.6]$ & .00 \\
\hline POD2 & $11.2[7.8 ; 13.4]$ & $8.6[6.1 ; 12.1]$ & .00 \\
\hline POD3 & $9.1[6.3 ; 11.3]$ & $7.6[4.9 ; 10.3]$ & .00 \\
\hline \multicolumn{4}{|c|}{ Living donor kidney } \\
\hline & $(n=84)$ & $(n=45)$ & \\
\hline POD1 & $17.0[13.0 ; 21.3]$ & $16.2[13.4 ; 20.7]$ & .30 \\
\hline POD2 & $11.6[9.1 ; 13.9]$ & $10.3[9.0 ; 13.8]$ & .37 \\
\hline POD3 & $9.1[7.0 ; 10.9]$ & $8.2[6.4 ; 10.0]$ & .09 \\
\hline \multicolumn{4}{|c|}{ Deceased donor kidney } \\
\hline & $(n=95)$ & $(n=67)$ & \\
\hline POD1 & $11.2[7.4 ; 15.1]$ & $9.0[6.3 ; 11.9]$ & .02 \\
\hline POD2 & $10.6[7.0 ; 13.3]$ & $7.1[5.2 ; 9.8]$ & .00 \\
\hline POD3 & $8.9[5.7 ; 11.8]$ & $7.0[4.3 ; 10.4]$ & .03 \\
\hline
\end{tabular}

Data are present as median [95\% confidence interval]

Good residual function group: 1 year eGFR $\geq 60$, Poor residual function group: 1 year eGFR $<60$

$P O D$ Postoperative day

converting-enzyme inhibitor/angiotensin-receptor blocker users and $41 \%$ in patients who did not use either type of drug.

Globally, the 1-year graft survival rate of overall KT is $>90 \%$, and this rate is gradually improving for deceaseddonor KT [29]. However, the 20-year transplanted kidney survival rate is $21 \%$ [30]. The method of raising the long-term survival rate of transplanted kidney is avoidance of known risk factors. Donor risk factors associated with graft failure are age $>60$ years, history of HTN, cerebrovascular cause of death, and pre-harvest serum $\mathrm{Cr}>150 \mathrm{~mol} / \mathrm{L}$ [31]. Risk factors measured in this study were age, hypertension and HLA mismatch. Recipient risk factors associated with graft failure include age,

Table 5 Relationship of residual kidney function and postoperative furosemide dosage (mg) of 1st, 2nd, and 3rd day

\begin{tabular}{lll}
\hline & Good residual function group & Poor residual function group \\
\hline All & $(n=179)$ & $(n=112)$ \\
POD1 & $40[20 ; 80]$ & $40[20 ; 80]$ \\
POD2 & $40[20 ; 80]$ & $40[20 ; 60]$ \\
POD3 & $20[20 ; 40]$ & $20[20 ; 40]$ \\
Living donor kidney & & \\
& $(n=84)$ & $(n=45)$ \\
POD1 & $40[20 ; 80]$ & $40[20 ; 80]$ \\
POD2 & $60[40 ; 100]$ & $60[40 ; 80]$ \\
POD3 & $20[20 ; 40]$ & $20[20 ; 40]$ \\
Deceased donor kidney & $(n=95)$ & \\
& $60[20 ; 80]$ & $(n=67)$ \\
POD1 & $20[20 ; 60]$ & $40[20 ; 60]$ \\
POD2 & $20[20 ; 40]$ & $20[20 ; 60]$ \\
POD3 & $20[20 ; 40]$ \\
\hline
\end{tabular}

Data are present as median [95\% confidence interval]

Good residual function group: 1 year eGFR $\geq 60$, Poor residual function group: 1 year eGFR $<60$ $P O D$ Postoperative day 
Table 6 Relationship of residual kidney function and postoperative mannitol dosage (g) of 1st, 2nd, and 3rd day

\begin{tabular}{llll}
\hline & Good residual function group & Poor residual function group & \\
\hline All & $(n=179)$ & $(n=112)$ \\
POD1 & $30[30 ; 30]$ & $30[30 ; 30]$ & .51 \\
POD2 & $30[30 ; 30]$ & $30[30 ; 30]$ & .39 \\
POD3 & $0[0 ; 30]$ & $30[0 ; 30]$ \\
Living donor kidney & & \\
& $(n=84)$ & $(n=45)$ \\
POD1 & $30[30 ; 30]$ & $30[0 ; 30]$ \\
POD2 & $30[30 ; 30]$ & $30[30 ; 30]$ \\
POD3 & $0[0 ; 30]$ & $0[0 ; 30]$ \\
Deceased donor kidney & $(n=95)$ & & .28 \\
& $30[30 ; 30]$ & $(n=67)$ \\
POD1 & $30[30 ; 30]$ & $30[30 ; 30]$ \\
POD2 & $30[0 ; 30]$ & $30[30 ; 30]$ \\
POD3 & $30[0 ; 30]$ & .35 \\
\hline
\end{tabular}

Data are present as median [95\% confidence interval]

Good residual function group: 1 year eGFR $\geq 60$, Poor residual function group: 1 year eGFR $<60$ $P O D$ Postoperative day

increasing plasma renin activity, BMI, prior transplant, dialysis at the time of $\mathrm{KT}$, and hepatitis $\mathrm{C}$ virus infection [32]. Our study also showed that recipient height, weight and BMI affect graft function. Navis et al. [33] reported that increased BMI was associated with increased glomerular filtration pressure, which adversely affected longterm graft survival.

In this study, postoperative viral infection was associated with the 1-year eGFR. There may be several types of viral infections after $\mathrm{KT}$, but CMV and BKV are common. Viral infections may affect acute or chronic rejection episodes. Reportedly, 72\% of CMV-positive recipients developed rejection, whereas CMV-negative recipients had only a $17 \%$ rejection rate [34]. The mechanism of CMV-induced allograft rejection is as follows. First, activation of HLA class I antigen-specific $\mathrm{T}$ cells due to cross-reactivity with CMV antigens. Second, release of inflammatory cytokines [eg, IL (interleukin) -1, IL-6, IL-8, and tumor necrosis factor- $\alpha$ ] and direct damage of endothelial cells. Third, these complex interactions not only increase the expression of HLA class II molecules in allogeneic grafts, but also produce

Table 7 Predicting DGF incidence with postoperative urine output using ROC curve

\begin{tabular}{ll}
\hline & AUC \\
\hline POD1UO & 0.913 \\
POD2UO & 0.984 \\
POD3UO & 0.944 \\
POD1UO + 2+3 & 0.969 \\
\hline
\end{tabular}

AUC Area under curve, PODUO Post-operative day urine output adhesion molecules of white blood cells and endothelial cells [35].

Finally, the results of this study show a correlation between the occurrence of rejection episodes and the 1year eGFR. Esteve et al. [36] reported that patients with rejection episodes were at increased risk of late graft failure. In addition, acute rejection episodes affected graft survival, regardless of the time of onset [37]. Immunosuppressant use is inevitable in $\mathrm{KT}$ patients to achieve control of rejection, but it renders the recipient susceptible to viral infection and reactivation [38].

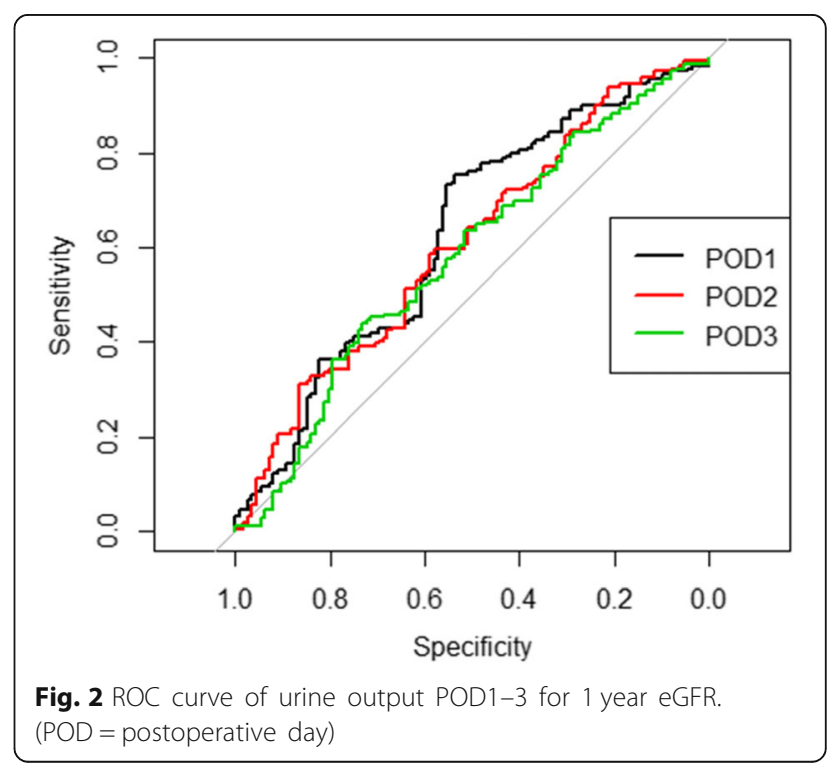


Table 8 Rejection episode

\begin{tabular}{llll}
\hline & $\begin{array}{l}\text { Good residual function } \\
\text { group }\end{array}$ & $\begin{array}{l}\text { Poor residual function } \\
\text { group }\end{array}$ & $\begin{array}{l}P \\
\text { value }\end{array}$ \\
\hline All & $(n=179)$ & $(n=112)$ & .00 \\
Positive & $9(5 \%)$ & $33(29 \%)$ & \\
& $170(95 \%)$ & $79(71 \%)$ & .00 \\
Negative & & \\
Living donor kidney & $(n=84)$ & $(n=45)$ & \\
Positive & $6(7 \%)$ & $16(36 \%)$ & .00 \\
Negative & $78(93 \%)$ & $29(64 \%)$ & \\
Deceased donor kidney & & \\
& $(n=95)$ & $(n=67)$ & \\
Positive & $3(3 \%)$ & $17(25 \%)$ & \\
& $92(97 \%)$ & $50(75 \%)$ & \\
Negative & & &
\end{tabular}

Data are present as number (\%)

Good residual function group: 1 year eGFR $\geq 60$, Poor residual function group: 1 year eGFR $<60$

In the present study, most KT were carried out by one surgeon and there were few variables due to surgery. However, this study has the following limitations. First, this study was retrospectively conducted in a single institution. Therefore, the sample size was small and there was no direct measurement of renin and aldosteron. However, it is known that renin and aldosterone levels are raised in deceased donor KT. Second, demographic

Table 9 Viral infection

\begin{tabular}{llll}
\hline & $\begin{array}{l}\text { Good residual function } \\
\text { group }\end{array}$ & $\begin{array}{l}\text { Poor residual function } \\
\text { group }\end{array}$ & $\begin{array}{l}P \\
\text { value }\end{array}$ \\
\hline All & $(n=179)$ & \\
Positive & $19(11 \%)$ & \\
& $160(89 \%)$ & $35(31 \%)$ & \\
Negative & $77(69 \%)$ & \\
Living donor kidney & & .00 \\
& $(n=84)$ & $(n=45)$ & \\
Positive $\quad 4(5 \%)$ & $13(29 \%)$ & .01 \\
Negative & $80(95 \%)$ & $32(71 \%)$ & \\
Deceased donor kidney & $(n=95)$ & & \\
Positive & $15(16 \%)$ & $(n=67)$ & \\
Negative & $80(84 \%)$ & $22(33 \%)$ &
\end{tabular}

Data are present as number (\%)

Good residual function group: 1 year eGFR $\geq 60$, Poor residual function group:

1 year eGFR $<60$ data are different between the groups (for example $\mathrm{BMI}$ ), so we tried to compensate for this difference by using urine volume per weight rather than postoperative urine output itself. Third, The incidence of DGF in this study was lower than in other studies [39]. This may reveal that postoperative urine output is a risk factor for the development of DGF, but is insufficient to explain the outcome of 1 year eGFR. Fourth, we used eGFR with MDRD to assess kidney function. This formula tends to be somewhat higher than the actual glomerular filtration rate in Asians, including Japan, and suffers from a slight drop in accuracy when glomerular filtration rate is normal or slightly decreased [40]. But, the MDRD equation was the most accurate of the creatinine-based equations [41]. Fifth, we did not analyze post-transplantation blood pressure control statuses of the recipients or the types of immunosuppressive drug used after KT.

\section{Conclusions}

Sufficient urine output after immediate KT reflects proper blood supply to the transplanted kidney and the absence of stenosis or leakage at the anastomosis site. Early postoperative urine output was associated with 1year postoperative graft function in deceased-donor kidney recipients, but not in living-donor kidney recipients. This difference may be caused by activation of the RAAS due to prolonged cold ischemic time during the preparation of deceased-donor kidneys. Therefore, we recommend that the approach to achieving proper urine volume after $\mathrm{KT}$ be adjusted depending on the type of transplanted kidney.

\section{Abbreviations}

BKV: BK poliomavirus; BMI: Body mass index; CMV: Cytomegalovirus; Cr: Creatinine; DGF: Delayed graft function; DM: Diabetes mellitus; EBV: Epstein-Barr virus; eGFR: Estimated glomerular filtration rate; ESRD: Endstage renal disease; HLA: Human leukocyte antigen; HTN: Hypertension; IL: Interleukin; KT: Kidney transplantation; MDRD: Modification of Diet in Renal Disease; POD: Postoperative day; RAAS: Renin-angiotensionaldosterone system; ROC: Receiver-operating-characteristic

\section{Acknowledgments}

The English in this document has been checked by at least two professional editors, both native speakers of English. For a certificate, please see: http://www.textcheck.com/certificate/eZ5njx

\footnotetext{
Authors' contributions

HBB and SJ participated in study conception and supervision of the research group. Manuscript editing. JK was involved with manuscript drafting and interpretation. JHK was involved with data analysis. SWS was involved with statistical analysis and manuscript drafting. TP was involved with manuscript editing. JIC was involved with data interpretation. All authors have read and approved the final manuscript.
}

\section{Funding}

This research received no specific grant from any funding agency in the public, commercial, or not-for-profit sector. 


\section{Availability of data and materials}

The datasets generated and analyzed during the current study are available from the corresponding author on reasonable request.

\section{Ethics approval and consent to participate}

This single-center retrospective cohort study was approved by the institutional review board (IRB) of Chonnam National Universitiy Hospital (IRB approval number: $\mathrm{CNUH}-2019-018)$. The informed consent was waived because of the retrospective nature of this study.

\section{Consent for publication}

Not applicable.

\section{Competing interests}

The authors declare that they have no competing interest.

\section{Received: 15 September 2019 Accepted: 3 December 2019} Published online: 17 December 2019

\section{References}

1. Hill NR, Fatoba ST, Oke JL, Hirst JA, O'Callaghan CA, Lasserson DS, et al. Global prevalence of chronic kidney disease - a systematic review and meta-analysis. PLoS One. 2016;11(7):e0158765.

2. Wolfe RA, Ashby VB, Milford EL, Ojo AO, Ettenger RE, Agodoa LY, et al. Comparison of mortality in all patients on dialysis, patients on dialysis awaiting transplantation, and recipients of a first cadaveric transplant. N Engl J Med. 1999;341(23):1725-30.

3. van Valenberg PL, Hoitsma AJ, Tiggeler RG, Berden JH, van Lier HJ, Koene RA. Mannitol as an indispensable constituent of an intraoperative hydration protocol for the prevention of acute renal failure after renal cadaveric transplantation. Transplantation. 1987;44(6):784-8.

4. Ciapetti M, di Valvasone S, di Filippo A, Cecchi A, Bonizzoli M, Peris A. Lowdose dopamine in kidney transplantation. Transplant Proc. 2009;41(10): 4165-8

5. Lachance SL, Barry JM. Effect of furosemide on dialysis requirement following cadaveric kidney transplantation. J Urol. 1985;133(6):950-1.

6. Othman MM, Ismael AZ, Hammouda GE. The impact of timing of maximal crystalloid hydration on early graft function during kidney transplantation. Anesth Analg. 2010;110(5):1440-6.

7. Bonventre JV. Kidney injury molecule-1 (KIM-1): a urinary biomarker and much more. Nephrol Dial Transplant. 2009:24(11):3265-8.

8. Matteucci E, Carmellini M, Bertoni C, Boldrini E, Mosca F, Giampietro O. Urinary excretion rates of multiple renal indicators after kidney transplantation: clinical significance for early graft outcome. Ren Fail. 1998; 20(2):325-30.

9. Osman Y, El-Husseini A, Kamal M, Refaie A, Sheashaa H, Sobh M. Does timing of post-renal transplant diuresis affect graft survival in live-donor renal transplants? BJU Int. 2011;107(2):284-7.

10. Morkane CM, Fabes J, Banga NR, Berry PD, Kirwan CJ. Perioperative management of adult cadaveric and live donor renal transplantation in the UK: a survey of national practice. Clin Kidney J. 2019;12:880-7.

11. Hanif F, Macrae AN, Littlejohn MG, Clancy MJ, Murio E. Outcome of renal transplantation with and without intra-operative diuretics. Int J Surg. 2011; 9(6):460-3.

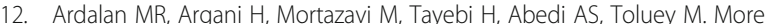
urine is better after renal transplantation. Transplant Proc. 2003;35(7):2612-3.

13. Lai Q, Pretagostini R, Poli L, Levi Sandri GB, Melandro F, Grieco M, et al. Early urine output predicts graft survival after kidney transplantation. Transplant Proc. 2010;42(4):1090-2.

14. Montas SM, Moyer A, Al-Holou WN, Pelletier SJ, Punch JD, Sung RS, et al. More is not always better: a case postrenal transplant large volume diuresis, hyponatremia, and postoperative seizure. Transpl Int. 2006;19(1):85-6.

15. National KF. K/DOQI clinical practice guidelines for chronic kidney disease: evaluation, classification, and stratification. Am J Kidney Dis. 2002;39(2 Suppl 1):S1-266

16. Santos J, Martins LS. Estimating glomerular filtration rate in kidney transplantation: still searching for the best marker. World J Nephrol. 2015; 4(3):345-53.

17. Khosroshahi HT, Oskui R, Shoja MM, Tubbs RS, Ardalan MR. Time-dependent variations in urine output after renal transplantation. Transplant Proc. 2007; 39(4):932-3
18. Levey AS, Eckardt KU, Tsukamoto Y, Levin A, Coresh J, Rossert J, et al. Definition and classification of chronic kidney disease: a position statement from kidney disease: improving global outcomes (KDIGO). Kidney Int. 2005; 67(6):2089-100.

19. White CA, Akbari A, Talreja H, Lalani N, Knoll GA. Classification of kidney transplant recipients using a combination of estimated GFR and albuminuria reflects risk. Transplant Direct. 2016;2(8):e96.

20. Huang Y, Tilea A, Gillespie B, Shahinian V, Banerjee T, Grubbs V, et al. Understanding trends in kidney function 1 year after kidney transplant in the United States. J Am Soc Nephrol. 2017;28(8):2498-510.

21. Dawidson IJ, Ar'Rajab A. Perioperative fluid and drug therapy during cadaver kidney transplantation. Clin Transpl. 1992:267-84. PMID: 1306705.

22. Maier HT, Ashraf MI, Denecke C, Weiss S, Augustin F, Messner F, et al. Prediction of delayed graft function and long-term graft survival by serum and urinary neutrophil gelatinase-associated lipocalin during the early postoperative phase after kidney transplantation. PLoS One. 2018;13(1): e0189932.

23. Mallon DH, Summers DM, Bradley JA, Pettigrew GJ. Defining delayed graft function after renal transplantation: simplest is best. Transplantation. 2013 96(10):885-9.

24. Notghi A, Anderton JL, Wilkinson SP, Chisholm GD. Significance of immediate diuresis in relation to transplant kidney survival rate. Int Urol Nephrol. 1986;18(4):453-5.

25. Lobo DN, Stanga Z, Aloysius MM, Wicks C, Nunes QM, Ingram KL, et al. Effect of volume loading with 1 liter intravenous infusions of $0.9 \%$ saline, $4 \%$ succinylated gelatine (Gelofusine) and $6 \%$ hydroxyethyl starch (Voluven) on blood volume and endocrine responses: a randomized, three-way crossover study in healthy volunteers. Crit Care Med. 2010:38(2):464-70.

26. Beckerhoff R, Uhlschmid G, Vetter W, Armbruster H, Siegenthaler W. Plasma renin and aldosterone after renal transplantation. Kidney Int. 1974;5(1):39-46.

27. Koller J, Wieser C, Kornberger R, Putensen C, Herold M, Schmid T, et al. Influence of the renin-angiotensin system of the organ donor on kidney function after transplantation. Transplant Proc. 1990;22(2):349-50.

28. Heinze G, Mitterbauer C, Regele H, Kramar R, Winkelmayer WC, Curhan $\mathrm{GC}$, et al. Angiotensin-converting enzyme inhibitor or angiotensin ॥ type 1 receptor antagonist therapy is associated with prolonged patient and graft survival after renal transplantation. J Am Soc Nephrol. 2006; 17(3):889-99.

29. Wang JH, Skeans MA, Israni AK. Current status of kidney transplant outcomes: dying to survive. Adv Chronic Kidney Dis. 2016;23(5):281-6.

30. Traynor C, Jenkinson A, Williams Y, O'Kelly P, Hickey D, Denton M, et al. Twenty-year survivors of kidney transplantation. Am J Transplant. 2012; 12(12):3289-95.

31. Pessione F, Cohen S, Durand D, Hourmant M, Kessler M, Legendre C, et al. Multivariate analysis of donor risk factors for graft survival in kidney transplantation. Transplantation. 2003;75(3):361-7.

32. Molmenti EP, Alex A, Rosen L, Alexander M, Nicastro J, Yang J, et al. Recipient criteria predictive of graft failure in kidney transplantation. Int J Angiol. 2016:25(1):29-38.

33. Bosma RJ, Kwakernaak AJ, van der Heide JJ, de Jong PE, Navis GJ. Body mass index and glomerular hyperfiltration in renal transplant recipients: cross-sectional analysis and long-term impact. Am J Transplant Off J Am Soc Transplant Am Soc Transplant Surg. 2007:7(3):645-52.

34. Lopez C, Simmons RL, Mauer SM, Najarian JS, Good RA, Gentry S. Association of renal allograft rejection with virus infections. Am J Med. 1974; 56(3):280-9.

35. Vanichanan J, Udomkarnjananun S, Avihingsanon $Y$, Jutivorakool K. Common viral infections in kidney transplant recipients. Kidney Res Clin Pract. 2018;37(4):323-37

36. Pallardo Mateu LM, Sancho Calabuig A, Capdevila Plaza L, Franco EA. Acute rejection and late renal transplant failure: risk factors and prognosis. Nephro Dial Transplant. 2004;19(Suppl 3):iii38-42.

37. Koo EH, Jang HR, Lee JE, Park JB, Kim S-J, Kim DJ, et al. The impact of early and late acute rejection on graft survival in renal transplantation. Kidney Res Clin Pract. 2015;34(3):160-4.

38. Kotton CN, Fishman JA. Viral infection in the renal transplant recipient. J Am Soc Nephrol. 2005;16(6):1758-74.

39. Irish WD, Ilsley JN, Schnitzler MA, Feng S, Brennan DC. A risk prediction model for delayed graft function in the current era of deceased donor renal transplantation. Am J Transplant Off J Am Soc Transplant Am Soc Transplant Surg. 2010;10(10):2279-86 
40. Levey AS, Stevens LA, Schmid CH, Zhang YL, Castro AF 3rd, Feldman HI, et al. A new equation to estimate glomerular filtration rate. Ann Intern Med. 2009;150(9):604-12.

41. Salvador $\mathrm{CL}$, Hartmann A, Asberg A, Bergan S, Rowe AD, Morkrid L. Estimating glomerular filtration rate in kidney transplant recipients: comparing a novel equation with commonly used equations in this population. Transplant Direct. 2017;3(12):e332.

\section{Publisher's Note}

Springer Nature remains neutral with regard to jurisdictional claims in published maps and institutional affiliations.

Ready to submit your research? Choose BMC and benefit from:

- fast, convenient online submission

- thorough peer review by experienced researchers in your field

- rapid publication on acceptance

- support for research data, including large and complex data types

- gold Open Access which fosters wider collaboration and increased citations

- maximum visibility for your research: over $100 \mathrm{M}$ website views per year

At BMC, research is always in progress.

Learn more biomedcentral.com/submissions 